\title{
Os enunciados da morte na constituição sócio-histórica do sujeito em mortificação e suicida
}

\author{
The death's enunciations in a socio-historical \\ constitution of the subject in mortification and \\ suicidal
}

\section{RESUMO}

Este artigo apresenta um estudo sobre a constituição sócio-histórica dos enunciados do homem e da morte no pensamento ocidental, a partir de dois referenciais teóricos: a arqueologia discursiva de Michel Foucault em As Palavras e As Coisas (1966), complementada pelos estudos da morte, referente à subjetivação mortificadora do louco em História da loucura (1961), estabelecendo-se uma ponte pela qual os saberes ocidentais situados em Foucault no Renascimento, Classicismo e Modernidade - se relacionam epistemicamente na constituição do sujeito em mortificação. Analisa os resultados apresentados em sua interface com a temática do sujeito suicida. Verificou-se que a constituição histórico-discursiva do sujeito em mortificação, mais do que uma verdade de natureza, está remetida a jogos discursivos historicamente situados. Em um processo de produção de redes de verdades, nas quais os enunciados da vida, do homem e da morte se interconstituem em um jogo de pressuposição recíproca, difusa e multifacetada, por meio do qual o sujeito suicida pode emergir enquanto resistência à normalização social.

Palavras-Chave: Foucault - Morte - Suicídio - Subjetivação - Discurso

\begin{abstract}
This study presents the socio-historical constitution of enunciations about man and death in occidental thought, starting with two theoretical references: Michel Foucault's Discursive Archeology in As Palavras e As Coisas (1966), complemented by the death's studies about the madman's irrational subjectivation in História da loucura (1961), establishing a bridge by which Occidental knowledge - situated in Foucault in the Renaissance, Classicism and Modernity - are related epistemically in the historicaldiscursive constitution of the subject in mortification. And it analyzes the results presented in its interface with the suicidal subject. It was verified that the historical-discursive constitution of the subject in mortification, more than a truth of nature, refers to the discursive arrangements historically situated. In a process of production of truths in which the enunciations of life, man and death interconstitute themselves in a reciprocal, diffuse and multifaceted presupposition, by which the suicidal subject can emerge as resistance to social normalization.
\end{abstract}

Keywords: Foucault - Death - Suicide - Subjectivation - Speech

* Doutor em Psicologia (USP), pós-doutor em Filosofia (UFSCar). Professor Associado de Psicologia e Humanismo da Universidade Federal de São Paulo. CV Lattes: http://lattes.cnpq.br/4032075843318626. 


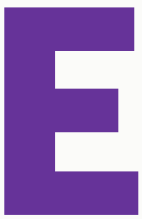

ste artigo reflete sobre a emergência sócio-histórica dos enunciados da morte no pensamento ocidental, a partir de dois referenciais teóricos: a arqueologia discursiva de Michel Foucault, que aborda a constituição do sujeito de conhecimento ocidental, presente na obra As Palavras e As Coisas (1966), complementada e ilustrada pelos estudos da morte, referente à construção social do comportamento irracional do louco em História da loucura (1961). Por fim, analisa os resultados apresentados em sua interface com a temática do sujeito suicida, a partir dos pressupostos arqueogenealógicos da filosofia de Foucault, seja sobre os jogos discursivos; seja sobre os preceitos da apropriação da vida e da morte pelos mecanismos de controle e vigilância social; seja sobre a constituição do biopoder, enquanto mecanismos multifacetados de disposição da vida e da morte para controles populacionais e de coletividades.

É importante ressaltar, em sentido amplo, que Foucault estuda, através de uma arqueogenealogia dos saberes, "a história das relações que o pensamento mantém com a verdade" (Escobar, 1984, p. 30). Como a correlação entre pensamento e verdade se estabelece na constituição de subjetividades locais, regionais e historicamente, conforme a seguir:

Através de quais jogos de verdade o homem se dá seu ser próprio a pensar quando se percebe como louco (História da loucura), quando se olha como doente (O nascimento da clínica), quando reflete sobre si como ser vivo, ser falante e ser trabalhador (As Palavras e As Coisas), quando se julga e se pune enquanto criminoso (Vigiar e Punir)? Através de quais jogos de verdade o ser humano se reconheceu como homem de desejo (História da Sexualidade)? (Escobar, 1984, p. 75).

Em As palavras e as coisas, suas investigações sobre a racionalidade dos saberes modernos na sociedade ocidental foram voltadas para o estudo dos saberes científicos em geral. Mais especificamente, sobre a questão do surgimento do homem, enquanto nova figura de conhecimento, a partir do advento da Modernidade, apropriada de maneira focal pelas denominadas ciências humanas, na ânsia de seus pesquisadores, quanto à consolidação de seus respectivos objetos de pesquisa, seja na Sociologia, na Antropologia ou na Psicologia. Ainda, analisando o que denominou de "a morte do homem", como evidência do esgotamento epistêmico dos saberes modernos em geral.

Sob viés específico, para Foucault, os enunciados de verdades são raridades, na medida em que demandam um esforço de pensamento para que se alcance sua expressão - a sua dizibilidade - que, frequentemente, só é perceptível pelo pesquisador a partir de uma análise de amplos períodos históricos. Por sua vez, vemos o estabelecimento de um jogo de pressuposição recíproca entre a raridade dos enunciados e a multiplicidade de sentidos deles advinda. Por exemplo, vemos pesar a reconhecível pluralidade de sentidos - compreendida enquanto "pletora do significado em relação a um significante único" (Foucault, 1969, p. 136) - que a enunciação da morte possa vir a comportar. Aliás, pluralidade esta evidenciada pelas variadas enunciações de verdades sobre o corpo morto releváveis nas obras de Foucault, embora não necessariamente constituam o foco central de seus estudos sobre a subjetivação dos múltiplos 
sujeitos de conhecimento, visto que a questão do sujeito homem - seja do ponto de vista discursivo, das relações de poder ou na constituição de uma estética da existência - surgia enquanto questão central em seus estudos. Porém, é reconhecível certas multiplicidades de relevos do sujeito morto, em Foucault, a partir de variados enunciados. Por exemplo: morte na alquimia, morte na catalogação dos seres vivos, morte na biologia, morte ou morbidez do louco, instinto de morte na constituição do sujeito psicologizado e psicanalisado, dentre outros.

A raridade da enunciação da palavra morte sobre a qual inúmeras formações discursivas se desenvolvem (por exemplo, a Biologia, a Psicologia, a Medicina, a Psicanálise, a Enfermagem, a Política, a Higiene, a Saúde Coletiva e Mental, a Religião), no entanto, sensibiliza-nos para a possibilidade de relevar suas dizibilidades, mediante amplas temporalidades, as quais não se relacionam diretamente com o suceder linear de eventos históricos, mas são constantemente associadas a certos rearranjos de dizeres na produção de conhecimentos. Para Foucault, episteme "não é uma forma de conhecimento ou um tipo de racionalidade que, atravessando as ciências mais diversas, manifestaria a unidade soberana de um sujeito, de um espírito ou de uma época", mas "é o conjunto das relações que podem ser descobertas, para uma época dada, entre as ciências, quando estas são analisadas no nível das regularidades discursivas" (Foucault, 1969, p. 217).

As emergências das raridades enunciativas no processo de formação de discursos e de conceitos foram analisadas na arqueologia de Foucault (principalmente em As palavras e as coisas), enquanto transformações epistêmicas. Portanto, sujeitas a um campo variado de relações, com suas rupturas e descontinuidades, nos processos de evolução histórica das mentalidades e dos saberes, relevando desta etapa as formações discursivas da morte (entrelaçadas às enunciações correlatas de vida e de homem), enquanto elemento importante no processo de subjetivação do homem moderno, seja como processo de autorreferência e conhecimento - principalmente no que diz respeito às instâncias mais instintuais do comportamento humano - seja na recíproca constituição de múltiplos enunciados sobre a constituição histórica do sujeito morto. Como veremos, também, neste artigo, a emergência dos enunciados de morte e morbidez é fundante na constituição de produções discursivas na invenção do sujeito louco em História da loucura.

Parte-se, portanto, do pressuposto de que a constituição histórico discursiva do sujeito morto, mais do que uma verdade de natureza, se remete a complexos jogos discursivos historicamente situados, no transcurso de macro momentos históricos, alguns deles milenares. Esta constituição histórico discursiva do sujeito morto emerge em um processo de produção de redes de verdades nas quais os enunciados da vida, do homem e da morte se interconstituem em um jogo de pressuposição recíproca, por meio do qual estes enunciados se remetem mutuamente, conforme será apresentado a seguir.

O enunciado da constituição do sujeito moderno: a entrada do homem na história em suas constituições correlatas com os enunciados da morte 
Foucault aponta, em As palavras e as coisas (1966), ao estudar a arqueologia das ciências humanas, três grandes fases do pensamento ocidental: a Renascença (por volta do século XVI), a Época Clássica (séculos XVII e XVIII) e a Modernidade (séculos XIX e XX). Até o fim do século $X V I$, a cosmologia da Renascença reconhecia semelhanças entre o homem e o macrocosmo, estabelecendo laços estreitos entre a natureza humana, os fenômenos da Natureza e a infinitude, de forma que "o mundo enrolava-se sobre si mesmo: a terra repetindo o céu, os rostos mirando-se nas estrelas e a erva envolvendo nas suas hastes os segredos que serviam ao homem" (Foucault, 1966, p. 33).

Construía-se o homem feito "espelho do mundo", a refletir os fenômenos da natureza e assemelhado aos reinos animal, mineral e vegetal. Esse homem, siderado, tendo a natureza dos seus corpos/almas projetada a uma Grande Ordem Celestial, por intermédio de discursos que vasculhavam similitudes entre a Natureza, o Macrocosmo e o microcosmo individual:

na vasta sintaxe do mundo, os diferentes seres se ajustam uns aos outros; a planta comunica com o animal, a terra com o mar, o homem com tudo que o cerca. A semelhança impõe vizinhanças que, por sua vez, asseguram semelhanças. O lugar e a similitude se imbricam: vê-se crescer limos nos dorsos das conchas, plantas nos galhos dos cervos, espécies de ervas no rosto dos homens; e o estranho zoófito justapõe misturando-as, as propriedades que o tornam semelhante tanto à planta como ao animal (Foucault, 1966, p. 34).

Sobre o homem se desdobravam as estrelas, as constelações, os elementos da natureza e uma rede de forças telúricas e cósmicas que se remetiam entre si, mútua e incessantemente. O homem se tornava apenas um elo de ligação, um ponto de contato e de suporte entre a diversidade de forças da natureza e a amplitude cósmica reconhecidas:

Existe, entretanto, nesse espaço sulcado em todas as direções, um ponto privilegiado (...): esse ponto é o homem; ele está em proporção com o céu, assim como com os animais e as plantas, assim como com a terra, os metais, as estalactites ou as tempestades. Erguido entre as faces do mundo, tem relação com o firmamento (seu rosto está para seu corpo como a face do céu está para o éter; seu pulso bate-lhe nas veias como os astros circulam segundo suas vias próprias; as sete aberturas formam no seu rosto o que são os sete planetas do céu); todas essas relações, porém, ele as desloca e as reencontramos, similares, na analogia do animal humano com a terra que habita: sua carne é uma gleba, seus ossos, rochedos, suas veias, grandes rios; sua bexiga é o mar e seus sete membros principais, os sete metais que se escondem no fundo das minas. O corpo do homem é sempre a metade possivel de um atlas universal ${ }^{1}$ (Foucault, 1966, p. 38).

De acordo com as palavras de Paracelso, "o homem descobrirá que contém 'as estrelas no interior de si mesmo [...], e que assim carrega o firmamento com todas as influências'"

1 Essas ideias de Foucault foram retiradas pelo pensador francês de uma obra do século XVIII: Crolliu, "Traité des signatures", Trad. Francesa, Lião, 1624, p. 88. 
(Foucault, 1966, p. 37), de tal forma que conceber o homem como foco de estudo separado do infinito simplesmente era inconcebível ou discursivamente impossível. Na mesma direção, tanto pelo texto de Croliu como pelos elementos que compõem a estrutura das analogias da mítica Árvore Alquímica da vida, o que se tem é o homem, por um lado, constelado às estrelas e, por outro, em interação com variados reinos dos seres viventes, em um jogo de semelhantes que tendia a combinações múltiplas e ao infinito, indicando seu caminho evolutivo mediante sua interação com todos estes universos naturais e telúricos, durante toda a vida, até a morte.

Tais jogos de semelhanças são monótonos, contudo, na medida em que não havia espaço para a constituição de um sujeito individualizado, mas apenas remetido aos demais seres e reinos que o circundavam. Assim, por exemplo, siderado às estrelas; ou constelado a planetas e agrupamento de estrelas na Astrologia (saber milenar, regido pelos sistemas de semelhanças); contendo elementos da Natureza (tal qual a Acupuntura, na qual órgãos são sedes do fogo, da água, da madeira, do metal, da terra). Cabe ressaltar que, sob a égide epistêmica dos jogos de semelhança renascentista, as analogias para a edificação de um saber sobre o homem enquanto enunciado primordial, produtor de verdade, o situava em múltiplos jogos de similitude e, no que nos interessa, ao reino animal, de forma a se criar um espaço discursivo intersubjetivador no qual as dizibilidades da vida e da morte se interremetem, em pressuposição recíproca, enquanto elemento representativo da terra às distantes dimensões estelares.

Estes jogos de semelhanças analógicos não abriam espaço para o enunciado de um sujeito aberto a individualizações e processos de identidade sobre eles cravados, possibilitadores de se dizer e de se ver sobre seus corpos, a emergência de fenômenos modernos da vida e da morte, mensuráveis e diagnosticáveis. O que se poderia enunciar é o advento da morte em contraponto à dimensão fenomênica do ser vivendo sua jornada, descrita na Árvore Alquímica da Vida enquanto experiência final comparável a um apagamento do microcosmo humano perante o Macrocosmo, enquanto seu espelho ou instância de retorno originária. Assim, homem morto feito estrela que se apaga, ou filho das estrelas, dos planetas, cujo espelho celestial de sua existência deixa de se manifestar. Ou chama de órgãos, madeira que se queima, metal que se esgota, água que seca, no jogo elementar da Acupuntura. Portanto, matéria que veio do pó e ao pó retorna...

Sob outra dimensão, ainda em vida, a morte surgiria enquanto elemento de transmutação alquímica, na busca do mago pelo elixir da Vida Eterna ou na Transmutação dos elementos da Natureza em ouro. Nesta perspectiva, o enunciado da morte representaria a dobra de transmutação de um ser para sua abertura para uma vida eterna; ou então, o resultado jubiloso de seu empenho ao transformar materiais, matando-os de sua natureza originária e fazendoos renascer, sob a forma de ouro.

Em ambos os casos, este processo laborioso se remeteria às similitudes de elementos alquimicamente manipulados, através dos quais residiriam, analogicamente, todos os reinos da natureza na produção da eternidade e do ouro. Seja do ponto de vista dos sujeitos, seja do ponto de vista dos materiais da alquimia, não há espaço para objetos definidos, mas para detentores de sinais de semelhanças entre estrelas, reinos animais, vegetais e minerais, gravados 
sobre seus corpos. Neste contexto, a morte é experiência-limite de esgotamento de tais jogos de semelhança, e não experiência ou tema individualmente considerado, pois, neste período, ainda não se consegue conceber a existência de sujeitos e objetos de conhecimento, nos moldes modernos, conforme será esclarecido adiante.

Outro campo discursivo valoroso para a compreensão da importância dos enunciados mortificadores na constituição identitária do sujeito humano diz respeito ao saber milenar, contido nas cartas de Tarot. Em seus vinte e dois arcanos maiores, constitutivos das imagens filosóficas e arquetípicas da jornada existencial humana, consideradas componentes da psiquê, a presença de figuras da morte é ostensiva em uma carta, "A Morte". Sua ilustração é composta por um esqueleto cortando, com uma foice vermelha - a cor do coração - todos os excessos existenciais dispensáveis e supérfluos, sobre um solo negro, cercado de pedaços de corpo humano. Esta imagem representa simbolicamente a dimensão das rupturas, separações, esgotamentos; além da manutenção apenas do essencial da vida, representado pela caveira; e também enquanto figura da morte para renascimentos e transformações renovadoras, na constituição da materialidade e da visibilidade do sujeito humano, em seu processo evolutivo enquanto ser-no-mundo.

Em linhas gerais, no Renascimento e perante saberes milenares, verifica-se a dominância da simbolização dos sujeitos mortos, em mortificação e da morte enquanto força-limite representativa, ambiguamente, tanto do esgotamento da existência humana quanto como limiares de renovação e transformação de suas experiências na constituição de verdadeiros portais - práticos e discursivos - de radicais transformações de sua existência.

Estas radicalidades limítrofes da experiência da morte podem ser remetidas, em sua dimensão abismal, tanto à loucura como à morte, ilustrada por pintores por meio da Dança Macabra, enquanto modalidade de gravura recorrente nos murais das igrejas medievais, que teria um sentido pedagógico, de exortação de que todos os seres humanos, independente da classe social - imperadores, plebeus, monges, aristocratas, juízes, médicos, sábios, dentre outros, em dança com a caveira da Morte - estão destinados à morte, como única certeza da vida. No sentido coletivo, à perdição social da moralidade, culminada no fim dos tempos do Apocalipse, a partir dos estudos pictóricos sobre o perecimento, na constituição discursiva das experiências trágicas da loucura.

\section{A morte na constituição discursiva das experiências trágicas da loucura}

É neste universo de saberes, nos quais a miséria humana alerta para os riscos da morte ameaçando corpos, almas e civilizações, que se vê emergir o enunciado da morte no transcurso da Idade Média e dos primórdios da Renascença, imerso nos jogos de semelhanças entre o micro e o macrocosmo, como espelho da experiência trágica da pequenez do homem, diante da infinitude do universo, em sua proximidade constante com a loucura e a morte. É o que ilustram os quadros de Bosch (1450-1516), de Brueghel (1525-1569), de Matthias Grünewald (14701528), de Thierry Bouts (1415-1475) e Dûrer (1421-1578), ao mostrarem, não só a mortificação, 
mas a própria realidade do mundo ensandecida, absorvida no universo de imagens fantásticas, atravessado pela ameaça da fome, da tentação, da fatalidade e das guerras. Nesse horizonte no qual selvageria, loucura e decadência civilizatória se remetem intrinsecamente, ainda no Renascimento, em torno do século $\mathrm{XV}$, a questão da morte na constituição do imaginário da peste - que dizimara um terço da população da Europa - é central na expressividade artística da fome, da insanidade e das guerras.

Em seu quadro "O triunfo da morte" (Bruegel, 1562), no qual o homem se defronta com a insanidade destrutiva das guerras, a experiência trágica de vitória da morte sobre a vida vem ressoar seus ditames fatídicos. Com um simbolismo mais intenso, em "Dulle Grete" (Bruegel, 1562), a rainha Margot provoca e lidera sua batalha desarrazoada de destruição e mortandade de seu próprio povo. Em "A tentação de Santo Antônio" (Grunewald, 1510/1562), o monge defronta suas aspirações espirituais, sendo tentado pela realidade mundana, cercado por um mundo bestial em extermínio e aniquilação material e moral. Em outro quadro, Bosch também ilustra o perecimento, em "A tentação de Santo Antônio" (1495/1450), com a presença de um ser-ogro e monstruoso, cercando-o por uma fauna de criaturas antropomórficas, retratos de uma humanidade em perdição e desrazão, no horizonte no qual decadência e morte se intercomunicam; também presente no quadro "O inferno (Bouts, 1450)", no qual a decadência humana se reporta à experiência infernal de seres mortos em estado de pecado.

Em outro quadro expressivo do fim do mundo, "Os quatro cavalheiros do apocalipse" (Dürer, 1497/1498) - emblemáticos da fome, peste, guerra e miséria - são conduzidos por quatro cavalos, como força motriz que conduz ao limiar da irracionalidade coletiva, na constituição de uma presença da morte como destino derradeiro, no horizonte do fim da humanidade. Com o advento da Época Clássica, no transcurso dos séculos XVII e XVIII, houve uma desvalorização das similitudes da Renascença e desses saberes ancestrais, revestindo-as de obscuridade, enquanto conhecimento vago, impreciso e, portanto, desqualificado. Repelida aos "confins do saber, [...] ela se liga à imaginação, às repetições incertas, às analogias nebulosas" (Foucault, 1966, p. 34), de forma a submetê-los a este manto epistêmico de obscuridade na riqueza de sua simbologia mortal, conforme será apresentado a seguir.

\section{A morte enquanto experiência-limite da conduta desarrazoada do homem nos renovados arranjos epistêmico-discursivos do Classicismo}

A Época Clássica foi, segundo Foucault (1966), um período de ordenação dos diversos seres vivos da natureza, com o intuito de estabelecer uma taxonomia da diversidade da vida no planeta, no processo de sistematização e de nomeação dos reinos animal, vegetal e mineral, aliada a um período histórico de descoberta e investigação de novos animais, minerais e vegetais advindos da descoberta de novos continentes. Em tal processo, a visibilidade de tais reinos se torna inteligível mediante o arrolamento sistemático destes seres em categorias diferenciáveis, numa tradição da filosofia natural setecentista na qual se alinhavam tanto os estudos de "Georges Cuvier (1769-1832) quanto de Étienne Geoffroy Saint-Hilaire (1772-1844) 
[os quais] viam o estudo do mundo natural como uma das possibilidades de se interpretar a obra divina" (Santos e Campos, 2014, p. 1216). Destaca-se também Carl von Linnaeus (17071778), cuja tarefa de ordenar e nomear o mundo pós-Criação "unia a natureza a Deus. Nesse sentido, ele conclui que a própria ideia lineana de ordenação refletia uma visão da Criação como sistema equilibrado e harmônico" .

Estudos mais recentes de Arthur Lovejoy (1873-1962) - em sua obra primordial "A Grande Cadeia do Ser" - vêm resgatar deste período Clássico a compreensão de que esta etapa do pensamento ocidental, a respeito do mundo natural dos Setecentos, "pressupunha uma contínua escala dos seres, em melhora linear e unidirecional ascendente" (Santos e Campos, 2014, p. 1217), na qual o homem emergiria como ponto mais alto da escala evolutiva dos seres vivos; de maneira que os demais seres e reinos se situariam nessa escala evolutiva, em graduações descendentes ao homem.

Foucault nega a existência das ciências da vida na Época Clássica (dentre elas, a Biologia), já que «até o fim do século XVIII, a vida não existe. Apenas existem seres vivos. Estes formam uma, ou antes, várias classes na série de todas as coisas do mundo" (Foucault, 1966, p. 75). Assim, o autor releva da enunciação da vida nesta fase seu sentido meramente taxonômico na universal distribuição dos seres. Pela facilidade de submissão catalográfica, os discursos dos reinos vegetais são preponderantemente ressaltados, pois são de mais fácil classificação do que as figuras móveis, tridimensionalmente volumosas e mais dispersas dos reinos animais. Até o próprio corpo humano e o dos animais, em sua anatomia complexa, seria relativamente menos incitado à discursividade dos saberes clássicos, já que mais densos para classificação do que as plantas em geral. Ambos só voltam a ocupar um local de destaque científico no fim do século XVIII, a partir dos estudos de Cuvier (Foucault, 1966, p. 152). Neste contexto, a morte apenas emerge enquanto limiar derradeiro da experiência de seres catalogados. Assim, a morte se situa como elemento categorial que permite estabelecer o tempo de vida de seres e reinos, na determinação da durabilidade e da extinção de raças, gêneros e espécies em determinadas taxonomias.

Do ponto de vista da irracionalidade humana, tendo como referência a constituição do sujeito louco a uma experiência trágica da irracionalidade do mundo da Renascença, no transcurso do século XVI - aqui exemplificada pelas ilustrações de um mundo enlouquecido por pestes, guerras, fomes, tentações, misérias, culmináveis no advento do Apocalipse -, teria emergido um novo humanismo entre inícios do século XVII e meados do século XVIII - principalmente em Brant, Erasmo e Calvino na configuração de novo período de produção do conhecimento, denominado de Classicismo. Este período histórico despia a loucura das alegorias metafísicas e transcendentais do Renascimento, ao considerar que a loucura do homem "nasce no coração dos homens" na medida em que ele "organiza e desorganiza sua conduta" não como efeito de um mistério ocultado, mas como fruto da prática moral do homem, no desvio do indivíduo do caminho da retidão (Foucault, 1961, p. 28).

Em outras palavras ao homem que cultivasse hábitos degenerados - embriaguez, práticas sexuais descontroladas, condutas intempestivas e violentas, aversão ao trabalho, dentre outros - estaria mais suscetível, na complexa correlação do seu corpo com sua alma, a 
se tornar um desatinado, um desarrazoado, na produção de um, desatino feito "forma relativa à razão" enquanto medida própria do homem correto, de maneira que "toda loucura tenha sua razão que a julga e controla, e toda razão sua loucura na qual ela encontra sua verdade irrisória" (Foucault, 1961, p. 30), não como irradiância - mítica e reveladora - mas como imagem do castigo do homem que erra e, portanto, que se expõe aos efeitos da própria inverdade delirante de seus atos. Este discurso da loucura configurado enquanto expressão da estreiteza de discernimento do homem desvairado em sua mesquinharia mundana possibilita o surgimento da experiência clássica da loucura, com consequências patentes na constituição dos discursos sobre a morte, agora, correlata a tais preceitos da desrazão e do desatino do sujeito desregrado, imoral e, portanto, à mercê de suas impulsividades mórbidas ou mortificadoras.

Este rearranjo dos enunciados-chave das experiências limítrofes deste novo sujeito desarrazoado teve seus efeitos na concepção de sensibilidade artística da época. Doravante, não estaria mais afeita à intensidade das cores das guerras e dos conflitos infernais e apocalípticos de um homem irracional e pecador, suscetível aos efeitos de sua morbidez e a da humanidade, mas ao alcance dos desatinos de seus próprios atos decadentes e fragilizadores da estrutura de sua racionalidade, já que considerados intencionadamente imorais. Em seu limiar extremo, faria emergir no seu corpo a expressividade grotesca de suas intempestividades deletérias, que culminariam com a experiência radical de sua intemperança e descontrole: o advento da morte.

Tais efeitos deletérios do seu ser decadente são, agora, ilustrados, por exemplo, nas gravuras cinzas e em preto e branco na série "Os caprichos" de Goya (1746/1828). Conforme Foucault (1966, p. 577) uma gravura emblemática desta série é "O sono da razão produz monstros", na qual um bando de corujas (cuja representação recorrentemente está associada ao sentido de depositário do instinto de saber humano) se aproxima do dormidor - escriba ou pintor - desvelando a ele sobre a fonte inconsciente e instintual de sua inspiração: sua matriz. Compreende-se que a imagem do dormidor não se refere apenas, ao ato concreto do indivíduo que dorme. Mas à dimensão simbólica pela qual ao homem que não se mantém em vigília diante dos seus atos, não constrói sabedoria e consciência da vida; e faz emergir, da dimensão inconsciente dos seus sonhos, monstros que fariam aflorar a sua desrazão, com efeitos enlouquecedores e mortificadores.

Esta transição de um Classicismo categorizador de condutas, já com enlevos de uma discursividade racionalista e cartesiana em consolidação, se depara com uma experiência discursiva humana na qual as escolhas do sujeito determinarão a configuração de sua existência, mais arrazoada ou desarrazoada. Ameaça na qual se transfere ao sujeito seu processo de escolha - mais inventivo e construtivo; ou mais decadente e imoral -, já sem o fundo de uma cosmologia no qual o homem se vê arrebatado pelos apelos da peste, da fome, da guerra, da miséria, da luxúria enquanto grandes forças que podem levar seu destino à sucumbência da tragédia absolutamente fatal de sua experiência na Terra. As figuras da morte emergem aqui como ilustrações - sejam de facetas de sua alma, bem como de outras pessoas que o cercam - das tensões de seus desejos na definição de suas escolhas, determinantes de sua perspectiva de vida e de seu destino: íntegro e arrazoado ou desintegrado e desarrazoado. Reitera-se: no 
limiar de seu desatino, encontra-se a precipitação trágica de sua experiência mortal.

$\mathrm{Se}$, durante o Classicismo, a natureza surgia como uma multiplicidade de reinos a serem esquadrinhados, sem que, contudo, houvesse espaço para o homem, a vida e a morte enquanto categorias distintas a serem discriminadas no quadro clássico, o advento da Modernidade estabelece novos horizontes de racionalidade, criando campos de produção e de dispersão de discursos em torno da questão do homem e de sua natureza finita, enquanto medida de todas as coisas e seres.

\section{O surgimento do homem, da vida e da morte enquanto medida de todas as coisas e seu efeito-medida perante o reino animal}

Como consequência da emergência da Modernidade entre a segunda metade do século XVIII e as primeiras décadas do século XXI, houve um reposicionamento discursivo do homem na História, que gerou uma nova formação dos demais seres vivos enquanto objetos do discurso, de modo que, "na representação, os seres agora não manifestam mais sua identidade, mas a relação exterior que estabelecem com o ser humano" (Foucault, 1966, p. 329). Doravante, o homem é o objeto central de um campo de verdades, passando a se destacar dos demais seres da natureza enquanto um domínio discursivo diferenciado e específico a ser estudado. Portanto, passa a servir como grade de especificação a renovadas conformações de saberes em produção, e ao qual todos os outros reinos da natureza deveriam se reportar.

Esta é a base epistêmica do humanismo moderno o qual, ao centrar a produção do conhecimento sobre a finitude do homem - em seu processo de nascimento, vida e morte - desconsidera a dimensão humana em sua transcendência divina, a qual era predominante nos jogos de semelhança do microcosmo humano perante o macrocosmo, no período do Renascimento, conforme já visto.

A partir de então, a Modernidade dessacraliza o sujeito humano e permite a emergência de um positivismo científico, a partir do qual apenas existe o que é confirmado pela verificação da ciência.

Esta desqualificação do pensamento mágico e transcendental de um homem em relação de semelhança ao cosmos - nos termos do Renascimento - é denominado por Weber de desencantamento do mundo (Thiry-cherques, 2009, p. 912).

Esta ruptura de sua identidade individual perante o divino - agora circunscrita apenas à possibilidade da sua existência enquanto ser vivente - promoveria uma vida sem sentido. Por outro lado, este tipo de materialismo se aproximaria, ainda segundo Weber, do ideário do sujeito capitalista, pelo qual só se releva, do homem, sua capacidade de produção e a extração de suas forças úteis, até a sua morte.

Esta novidade histórico-epistêmica do surgimento do homem como medida de produção de conhecimento perante os demais reinos permitiu o surgimento de uma gama de saberes sobre os quais o advento da vida e da morte passaram a ter visibilidade discursiva, enquanto enunciados-chave do homem. A biologia, por exemplo, emerge para estudar a vida 
do homem enquanto referência para a compreensão dos limites mortais de sua existência e de todos os seres vivos. A economia poderá estudar os processos de produção de bens, necessidades e desejos dos homens, tendo a morte como limiar da consumação da vida no controle populacional das produções econômicas. A semiologia apresentará a emergência da linguagem do homem, situando a expressividade da morte enquanto espaço da nãolinguagem ou, dependendo da teoria, enquanto espaço de expressividade fenomênica e corporal derradeira da presença do ser-no-mundo dentre a miríade infinita de possibilidade de produção de discursos. Todas as novas disciplinas passaram a ter o homem como referencial central na construção de verdades para as quais os demais reinos então, se voltam para reportarem suas vidas e mortes.

$\mathrm{Na}$ intercomunicabilidade de vários discursos surge a Tanatologia científica moderna. Seus primórdios podem ser situados em 1903, quando o cientista microbiologista russo Élie Metchnikoff (1845-1916) estabeleceu os primeiros estudos interdisciplinares entre medicina e biologia na constituição de horizontes constitutivos da Medicina Legal e Forense. Em sua atuação se destacam seus estudos sobre a natureza humana em seu processo de envelhecimento e morte, como os presentes na obra "Estudos sobre a Natureza Humana. Ensaio de Filosofia Otimista" (1903).

Sob a égide do mesmo humanismo moderno, é possivel observar a emergência dos estudos sobre os instintos de vida e de morte, na psicanálise de Sigmund Freud (1856-1939), relevantemente formulados em sua obra, "Além do Princípio do Prazer" (1920 [1996]).

Como também, a filosofia existencial de Martin Heidegger (1889-1976), fundada na questão do ser-para-a-morte, com destaque, em "Ser e Tempo" (1927 [1986]); bem como a emergência singular de uma psicologia da morte, presente em Herman Feifell (1915-2003), através de sua obra: "O Significado de Morte" (1959), dentre outros pioneiros deste novo jogo enunciativo sobre a derradeira finitude da natureza humana.

É justamente esta definição do homem como medida para todos os reinos da natureza que se tornou um dos deslocamentos mais marcantes empreendidos pelo efeito de conjunto provocado pela Modernidade, de forma que o homem, antes excluído - ou apenas um elemento dentre outros - do quadro clássico, torna-se o elemento central da coordenação dos saberes científicos em geral. Esta métrica humanista dos saberes emerge de maneira que "o homem aparece com sua posição ambígua de objeto para um saber e de sujeito que conhece" (Foucault, 1966, p. 328).

Comparativamente às outras duas fases do Pensamento Ocidental aqui citadas, se na Renascença havia "uma metafísica da representação e do infinito" e no Classicismo "uma análise dos seres vivos", na Modernidade se configura "uma analítica da finitude e da existência humana" (Foucault, 1966, p. 333), sem a qual a dizibilidade da morte não seria possível nos moldes objetivadores modernos, tanto do homem como de todos os demais reinos. Assim, no fim do século XVIII ocorre a entrada do homem na história. Trata-se da mutação de conformação discursiva denominada de analítica da finitude do homem: "é uma analítica [...] em que o ser do homem poderá fundar em sua positividade todas as formas que the indicam não ser infinito" (Dreyfus e Rabinow, 1995, p. 22). A partir de tal reconfiguração discursiva, o homem passa a 
ser delineado como uma figura passível de pesquisas empíricas, alicerçada sobre sua própria finitude. O corpo torna-se um novo universo a ser vasculhado, analisado e exaustivamente estudado, enquanto objeto de investigação distinto e discriminado. Em outras palavras, "um ser cuja finitude the permite tomar o lugar de Deus" (Dreyfus e Rabinow, 1995, p. 32).

O processo de nascimento, vida e morte do homem - até então desconsiderado pela similitude cósmica dos jogos renascentistas, visto que a eles o homem só se remeteria enquanto microcosmo, espelho pueril e pontual do infinito; como também desconsiderado no Classicismo, já que não enunciado nas taxonomias dos reinos minerais, vegetais e animais. Doravante, serão objeto de esquadrinhamento de múltiplos saberes científicos modernos, já que o processo de finitude (e, portanto, de decadência e falência da vida humana) servirá de molde disciplinar para o desenvolvimento de correlações para a edificação das ciências tanatológicas - passando, então, a ser elemento central da produção do sujeito de conhecimento moderno, seja diretamente, como é o caso da já citada Tanatologia; seja indiretamente, enquanto saberes transversais humanistas que venham ser aplicados, de maneira adaptada, ao contexto da realidade mortificadora, dentre eles, a Medicina, a Biologia, a Psicologia, a Psiquiatria, a Fisioterapia, a Nutrição, a Educação Física, dentre outros.

Dentre os elementos centrais da finitude humana, os dizeres do suicídio passarão a ocupar um lugar central de fonte de empiricidades de pesquisas, na produção de verdades transcendentais, constituidoras de amplos processos mortificadores do sujeito morto na Modernidade. Desse momento em diante, o suicídio passa a ser articulado, não apenas enquanto categoria de conduta de um sujeito imoral, mas como modalidade de comportamento biologizável, psiquiatrizável, psicologizável, patologizável. A figura da morte consiste em elemento-chave de tais empoderamentos dos saberes modernos, conforme analisarei a seguir.

\section{Interfaces entre os enunciados da morte na constituição do sujeito suicida}

Do século XVIII até os dias de hoje, a morte é colocada enquanto enunciado-chave para a compreensão das experiências limítrofes de manutenção da vida e da sanidade humanas, constantemente emblemáticas da desumanização do homem em função, por exemplo, de doenças físicas e mentais; de condutas criminosas movidas por paixões ou desvarios; de vulnerabilidades sociológicas nas quais as condições sub-humanas produzem seres com instintos mais mórbidos do que outros, dentre outras formações discursivas possíveis.

Nessa miríade de figuras, os sujeitos mortificáveis ou com tendências suicidas se tornam discursivamente visíveis por suas condutas, que colocam em riscos vidas, afetos, parcerias e horizontes, justificando seus enjaulamentos, seja em hospícios ou prisões.

Em contrapartida, quando não enjaulados, esses indivíduos são subjugados à cotidianidade de amplos processos disciplinares e normalizadores, presentes nas fábricas, escritórios, quartéis, conventos, setting terapêuticos ou salas de aula, enquanto formas de transmutar sua morbidez em produção em série capitalista. Afinal, como diz o ditado: "o ócio é a casa do demônio" e se loucura é "a ausência de obra", o suicídio pode ser a experiência 
derradeira da produção de um sentido diante do esvaziamento normalizador e disciplinador da sociedade contemporânea.

É reconhecível que o suicídio é um ato ritual. Na cotidianidade de nossas vidas, ele não emerge entre nossos atos corriqueiros do dia-a-dia. É uma ascese produtora de sentidos, de desejos e, portanto, de subjetividade singular. Este modo de ser, na sua complexa relevância fenomênica e historicamente situada, não se reduz ao olhar tecnicista e objetivador dos saberes modernos, os quais, na interface psicologizadora, psiquiatrizadora ou socializadora, possa ver esta atitude ritualística enquanto anomalia, aberração e monstruosidade perante a preservação da vida. Considera-se que a objetivação desta experiência fenomênico-histórica interessa, de fato, aos detentores desses saberes instituídos no sentido de "sequestrarem" corpos e almas à égide do alcance de seus dispositivos de poder esquadrinhadores, medicalizadores, terapeutizantes dos sujeitos praticantes destes rituais derradeiros.

Não se considera tal conduta redutível à discursividade sentimentalista a partir da qual se vitimizam familiares, amigos e ambiente social circundante ao ato, constantemente considerado "egoísta" e "surpreendente" do suicida, que a todos arrebata em dor e sofrimento psíquico. Considera-se que vivemos em uma sociedade confessional, vigiada a partir das alteridades dos outros, que são nossos familiares, amigos e colegas de trabalho. Segundo esse desenho, no qual o outro se impõe enquanto medida normalizadora de nós próprios, a solitude da experiência suicida, mais do que uma experiência negativa de cessação da vida, pode ser concebida como um ato positivo de resistência aos mecanismos domesticadores de uma sociedade estruturalmente neurotizante e escravizadora.

Tal posicionamento possibilita uma aproximação com Durkheim, que sustenta a afirmação de que o "suicídio não é uma causa individual, mas sim uma causa social, pois segundo ele cada sociedade tem em sua história um conjunto de indivíduos dispostos ao suicídio, onde essa disposição deve ser estudada não apenas pelos fenômenos orgânico-psíquicos ou do meio físico no qual os indivíduos estão situados, mas sim segundo as causas sociais que geram os fenômenos coletivos" (Durkheim, 2004, p. 50). Quando o sujeito não é considerado enquanto singularidade, a conduta suicida pode vir a representar um gesto derradeiro de afirmação de si, perante o mundo cristalizador de identidades: um grito derradeiro e solitário de afirmação de si, enquanto estratégia ritualizada premeditada e, muitas vezes, comunicada por escritos, gravações de fitas, vídeos e imagens socializadas nas múltiplas formas de redes sociais.

Não se trata de fazer uma apologia da prática suicida, mas de retirar de seu bojo o vetor negativo de atitude simultaneamente demonizável, exclusivista e egoísta, de um sujeito insensivel à dor dos seus pares ou ao investimento que a sociedade impingiu sobre ele, durante toda a sua existência. Nesse sentido, para Durkheim, o suicídio é explicado enquanto fenômeno social, associado ao nível de coesão social que se estabelece na interação entre os sujeitos de determinada sociedade. Quanto mais isolacionista e coercitiva foi uma sociedade, no sentido de impor valores exteriores e gerais, sem considerar o indivíduo como singularidade e expressividade ímpar, maiores serão os índices de suicídio em uma sociedade.

O que está em jogo é tematizar que estar do lado da vida da maneira inadvertida e zelosa pela qual as populações são educadas seria estar em conformidade com a incitação 
capitalista de submissão dos corpos aos apelos da produção em série, mesmo em seu efeito contingentemente colateral de consumação da vida, e de seu sentido mediante a mecanização dos seres e de sua expressividade. É importante abrir espaço para emergências de dispositivos de biopoder - compreendidos enquanto exercício de poder exercido sobre os corpos, por intermédio da incidência de múltiplos dispositivos de dominação - que fundem as bases historicamente discursivas para a emergência de mecanismos de controle, higienização, repartição e disciplinarização, seja de indivíduos, grupos ou populações, muitas vezes norteados por dizeres que trazem, no cerne da inspiração da vitória da vida sobre a morte, o ideário diagramador da domesticalização de sujeitos. Tal domesticação se daria por meio da submissão dos impulsos mórbidos e instintos de auto consumação considerados primitivos e animais, moldáveis por sistemas de recompensa, de reforço e de extinção de comportamentos, desejados ou repulsivos. Tais sistemas possuem nos modernos discursos de diversos ramos da Psicanálise e da Psicologia os fundamentos teóricos que legitimam tanto a manicomialização como a medicalização ostensiva de grupos de suicidas em potencial. Esses, na maioria das vezes, são afetados pelas transversais dos discursos sociológicos que podem situá-los abaixo da linha da pobreza, como sujeitos sub-humanos, quase animais e, portanto, mais mórbidos do que os demais seres humanos mais normais - e com mais instinto de vida.

Aliás, situa-se a compreensão de medicalização àquela contextualização desenvolvida por Foucault pela qual medicalizar é "um dispositivo central do exercício do que se chamaria de nascimento da biopolítica, exercendo-se por meio da pedagogização do sexo da crianças, da histerização das mulheres, da psiquiatrização das perversões - cada um conduzindo a uma medicalização minuciosa dos corpos e, especificamente, da sexualidade, em nome da responsabilidade na saúde da prole, da solidez da instituição familiar e da sociedade" (Zorzanelli, Ortega e Bezerra, 2014, p. 1861).

É neste contexto que as peculiaridades do sujeito suicida estão inseridas e são reinventadas no dispositivo de medicalização, seja no âmbito "do processo de medidas coletivas do Estado na contenção, controle e registro de doenças, bem como na formação de práticas de salubridade" (Zorzanelli, Ortega e Bezerra, 2014, p. 1861); no que se refere à submissão dos corpos e dos sujeitos à prerrogativa de que, a partir do pós-Segunda Guerra, esses não são elementos exteriores aos saberes médicos; na produção histórico-discursiva da "impossibilidade de descrever experiências com o corpo humano que não passem, em algum sentido, pelo saber médico" (Zorzanelli, Ortega e Bezerra, 2014, p. 1861); ou na justificativa dos preceitos reacionários pelos quais os indivíduos improdutivos e desapegados à conservação da vida têm uma vida que não mereça ser vivida, já que destoam do esquadrinhamento social vigente.

Também é importante ressaltar que a mortificação do ser humano se acentua perante as classes menos favorecidas e mais suscetíveis à vulnerabilidade social. Isto se deve a discursos que culpabilizam tais sujeitos pelos seus infortúnios, considerando que são suas condutas imorais - avessas aos ditames disciplinadores e ordenadores da sociedade - que produziriam sua vida infame, e não a ausência de política públicas inclusivas, promotoras de melhores condições de educação e de saúde; enfim, de realização existencial. Dentre eles, 
por exemplo: "não trabalha, pois, é um inerte, um morto-vivo"; "não estuda, pois, é tapado feito uma múmia"; "é louco pois prefere vegetar até morrer"; "para morrer só falta deitar". O que ocorre num processo no qual quanto mais vulnerável socialmente se situa o sujeito nos esteios inferiores da escala social mais se psicologiza sua conduta, responsabilizando-o enquanto sujeito gerador de seus próprios atos mórbidos. Atos esses que produziriam sua vulnerabilidade socialmente situada de maneira expiatória, com menor responsabilização de gestores sociais em suas evidenciáveis políticas de produção coletiva de processos mórbidos socialmente consideráveis, de forma a se converter os espaços de normalização, cristalização e exclusão das identidades sociais, em funestos necrotérios de homens mortificáveis, no que exista de pior na acepção da exuberância da experiência de viver e morrer.

A constituição dessas múltiplas vulnerabilidades mortificáveis - sociais, políticas, sexuais, educacionais, éticas - se remete, constantemente, a processos seculares de espoliação, colonização e submissão dos corpos pelo controle de ideários excludentes, de cunho fascista e amplamente normalizador de condutas, redutores do sujeito humano ao parâmetro burguês, caucasiano, disciplinar, monogâmico e heterossexual vigente. Em tais processos, o sujeito subjugado acorda de manhã sempre disposto a passar a sua vida submisso ao mecanismo de produção, cercado pela sua vitalizada família, modelo de propaganda de margarina.

Os aspectos aqui sinalizados abrem espaço para estudos genealógicos sobre a produção de poderes e saberes sobre os corpos, os quais demandariam um estudo à parte, para além da proposição arqueológica discursiva deste artigo. Em um movimento epistêmico tais discursos produzidos no arcabouço moderno do humanismo mais do que efetivamente produzem garantias sociais e condições reconhecíveis de qualidade de vida, diagramando corpos e almas sob a intensidade de práticas discursivas multifacetadas, as quais, na contemporaneidade, ressoam o eco não só do período epistêmico recente mas de todas as articulações discursivas ancestrais, algumas centrais, elencadas neste trabalho.

O enunciado morte se remete à figura do monstro, da besta, do demônio, do descontrolado, do imoral, do impulsivo, do desejoso, do antissocial, em uma dizibilidade que custa ser proferida, já que entremeada de tabus de interdição e de mutismo. O que se dá principalmente diante da experiência familiar e social do suicida, com sucesso, desistente ou fracassado em sua extinção da vida. Experiência localizada no espaço discursivo da morte enquanto sede, simultaneamente, da raiz e do destino primitivo de nossos mais graves defeitos e comportamentos ostensivamente grotescos, na medida em que se naturaliza a preservação da própria vida e dos outros à esfera de um direito/dever natural e universal, inalienável e indisponível, na emergência - ancestral, secular, atual e historicamente sedimentada - da evocação das figuras mortificadoras e vivificadores da existência humana enquanto elementoschave entrelaçados na produção enunciativa de sujeitos historicamente situados.

Emergência que, constantemente, oculta a sombra humana pela qual, secularmente, ocorrem genocídios sistemáticos - tanto de humanos como de animais - por motivos vários: por interesses econômicos, de extração de forças úteis de seus corpos em indústrias e laboratórios científicos, como em experimentos pseudocientíficos em campos de concentração, conforme ocorreu na Segunda Guerra Mundial; pelo próprio processo sistemático socialmente 
constituído de esgotamento das forças úteis de cada indivíduo, em múltiplas redes de produção e de fixação dos corpos em instituições, por toda a sua vida (dentre elas, a acadêmica, da qual fazemos parte); enquanto objeto de autoafirmação na qual o exercício de experiênciaslimite entre jovens ${ }^{2}$ vem reduzir a experiência potencial do suicídio a um movimento lúdico de coagida ostentação perante seus pares; ou, por fim, por mero esporte, através do qual o homem descarrega sua própria monstruosidade, diante da sua própria existência, através de roletas russas e esportes arriscados.

Diante das multifaces discursivas da História da Humanidade, os sujeitos humanos vivificáveis ou mortificáveis - se reinventam, conforme apresentado neste artigo, na edificação de saberes, ciências e dizeres entrecortados e entrelaçados. Para o momento, só nos vislumbra compreender que podemos, cada um, na microfísica de nossas posições históricas e sociais, sermos reinventores de discursos e práticas sociais que renovem, resistente e estrategicamente, os sujeitos - vivificáveis ou mortificáveis - que habitam nossos seres, corpos e almas, enquanto construções e reconstruções históricas de nós mesmos e de todos os seres vivos do planeta e de nossas racionalidades e irracionalidades, através deles, reafirmadas, reformuladas e espelhadas, no transcurso criativamente angustiante de nossas finitas existências.

Retirando do sujeito mortificável ou suicida a pecha negativa de um negligente perante seu destino, diante de seu enquadramento afetivo e normalizador de determinada sociedade, este artigo vem abrir espaço para os estudos e reflexões da conduta suicida enquanto apelo terminal de certo exercício de resistência diante de uma sociedade higienista e normalizadora que, a princípio, intenciona extrair de nossos corpos forças úteis e dóceis na concepção mais escravagista e esgotadora de horizontes existenciais que a sociedade de controle contemporânea possa nos ofertar e nos diagramar. Sem apologias e sem avisos, mas ritualizado. Sem ânsia de compreensão de ninguém e, muitas vezes, em tensão na relação de si para consigo mesmo, o suicida grita e resiste, principalmente ao vetor negativo, jurídico e psicanalisador a partir do qual se pressupõe que sua conduta é uma aberração - psicológica, sociológica e antropológica - a ser esquadrinhada nos espaços farmacológicos de contenção química e, muitas vezes, física. Sem considerar que o eco histórico de sua prática reverbera nos contextos minuciosamente diagramados de uma sociedade cinza, modorrenta e disciplinar enquanto a vida que, à quase totalidade de nós, nos resta a regurgitar no ramerrão de nossas rotinas empalidecedoras e arrastadas. Restando-nos, ouvir do suicida seu apelo derradeiro, lembrando que a vida é intensa e sangra.

\section{Referências Bibliográficas}

DREYFUS, Hubert, e RABINOW, Paul. Michel Foucault: Uma trajetória filosófica. Rio de Janeiro: Forense Universitária, 1995. 384p.

2 Dentre eles, o jogo suicida baleia azul, por meio do qual, através de 50 desafios, propostos diariamente por um "curador", em grupos fechados nas redes sociais, o jogador desenvolve atividades simples - por exemplo, assistir a um filme de terror, desenhar uma baleia numa folha, tatuar uma baleia no braço - as quais culminariam com o suicídio do participante no último desafio; sufocar-se com travesseiro ou impedindo a respiração, individualmente ou induzido por colegas 
DURKHEIM, Émile. As Regras do Método Sociológico. São Paulo: Martins Fontes, 2004. 163p.

ESCOBAR, Carlos Henrique de (Org.). O Dossier: Últimas Entrevistas de Michel Foucault (19261984). $1^{\text {a }}$ ed. Rio de Janeiro: Livraria Taurus, 1984. 140p.

FEIFEL, Herman. The meaning of death. New York, NY: McGraw-Hill, 1959. 386p.

FOUCAULT, Michel. A História da Loucura na Idade Clássica. 5. ed. São Paulo: Perspectiva, 1961. $607 p$.

FOUCAULT, Michel. As Palavras e As Coisas: Uma Arqueologia das Ciências Humanas. São Paulo: Martins Fontes, 1966. 502p.

FOUCAULT, Michel. A Arqueologia do Saber. Rio de Janeiro: Forense Universitária, 1969. 264p.

FREUD, Sigmund. Além do princípio de prazer, 1920. In: Além do princípio de prazer. Rio de Janeiro: Imago, p. 11-75, 1996.

HEIDEGGER, Martin. Ser e Tempo. 2 vols. 10ª ed. Petrópolis: Ed. Vozes, 1986. 587p.

METCHNIKOFF, Élie. Etudes sur le Nature Humaine. Essai de philosophie optimiste. Masson, Paris, 1903. 442p.

SANTOS, Christian Fausto Moraes dos e CAMPOS, Rafael Dias da Silva; Apontamentos acerca da Cadeia do Ser e o lugar dos negros na filosofia natural na Europa setecentista. História, Ciências, Saúde - Manguinhos. Manguinhos, v. 21, n. 4, out./dez. 2014, p. 1215-1234. Disponível em: $\quad<$ http://www.scielo.br/pdf/hcsm/v21n4/0104-5970-hcsm-S0104-59702014005000017. pdf>. Acesso: 05/07/2019.

THIRY-CHERQUES, Hermano Roberto. Max Weber: o processo de racionalização e o desencantamento do trabalho nas organizações contemporâneas. Revista de Administração Pública. Rio de Janeiro, v. 43, p. 898-918, jul./ago. 2009. Disponível em: http://redalyc.org/ articulo.oa?id=241016445007 ISSN 0034-7612. Acesso: 05/07/2019

ZORZANELLI, Rafaela Teixeira, ORTEGA, Francisco, e Bezerra Júnior, Benilton. Um panorama sobre as variações em torno do conceito de medicalização entre 1950-2010. Ciência \& Saúde Coletiva. Manguinhos, v. 19, n. 6, p. 1859-1868, 2014.

Recebido em: 20 de outubro de 2018.

Aprovado em: 21 de abril de 2019. 